\title{
PERSONAL MEANING OF ACADEMIC EXPERIENCE: A COMPARISON OF INTRINSICALLY AND EXTRINSICALLY MOTIVATED GRADUATE STUDENTS
}

\author{
Anita Pipere \\ Daugavpils University, Latvia \\ Dzintra Iliško \\ Daugavpils University, Latvia
}

\begin{abstract}
To analyse the similarities and differences in personal meaning of academic experience associated with intrinsic and extrinsic academic motivation, the conceptual ideas of Self-Determination theory were blended with methodological elaborations based on the Dialogical Self Theory. The Academic Motivation Scale to identify intrinsically and extrinsically motivated graduate students and the Self Confrontation Method to disclose the important experiences in past, present and future related to the graduate studies were administered to 128 graduate students at the Daugavpils University. Both the quantitative and qualitative data analysis contributed to the understanding of relationships between the types of academic motivation and personal meaning of academic experience. The main differences in students' personal meaning of academic experience, expressed in narrative themes were following: self-development, ideas about the further studies and factors inhibiting graduate studies were more frequent for intrinsically motivated students, while external support from influential persons, work/career, and past experience influencing current academic life were mentioned more often by extrinsically motivated students. The obtained results may help to develop more effective teaching strategies and institutional support of graduate students.
\end{abstract}

Keywords: academic motivation; dialogical self; extrinsic motivation; intrinsic motivation; graduate students; personal meaning; self-determination.

\section{Introduction}

The interrelations of students' cognitive, emotional, motivational, and volitional processes are an emerging focus in educational psychology (Eyende \& Turner, 2006). Personal meaning of academic studies has been studied quite seldom, usually by qualitative approach and small samples. Personal meaning of academic studies for differently motivated graduate students has not been studied yet. To feel satisfied with college life and to present good academic performance, students need to adjust well to the personal and social changes while sustaining their motivation for studies (Astin, 1993; Baker \& Siryk, 1984). To compare the personal meaning of academic experience for students with intrinsic and extrinsic 
Pipere \& Iliško, 2018. Personal Meaning of Academic Experience: a Comparison of Intrinsically and Extrinsically Motivated Graduate Students

academic motivation, the main ideas of Self-Determination Theory (SDT) will be blended with the methodological views based on Dialogical Self Theory (DST).

The SDT originated by Ryan and Deci (2000) has been used frequently to study the academic motivation. SDT is a macrotheory that relates to human motivation focusing on how personal motives are integrated and regulated within the self and shows how the self internalises values, goals, and intentions in different social contexts (Deci \& Ryan, 2014). Fostering the fulfillment of autonomy, competence and relatedness we produce self-determined behaviours or intrinsic motivation, while thwarting these needs results in less self-determined behaviours or extrinsic motivation. The motivation can be expressed through a continuum of decreasing self-determination with three fundamental positions reflecting the degree of autonomy (Stover, de la Iglesia, Boubeta, \& Liporace, 2012): the intrinsic motivation is featured by a desire to seek new challenges, to explore and learn, extrinsically motivated behaviours are performed for some consequence external to the task itself, such as acquiring rewards or avoiding punishment (Ryan \& Deci, 2000), while amotivation signifies the individual's perception of lack of control over events, incompetence and absence of purpose.

It seems that intrinsic and extrinsic factors independently, but concurrently influence academic performance and behavior (Lepper, Corpus, \& Iyengar, 2005), though, autonomous motivation is considered to be high-quality motivation, whereas controlled motivation is viewed to be of low quality (Deci \& Ryan, 2000, 2008). SDT also shows that knowing whether students' motivation is more autonomous or controlled is more important for predicting their schoolrelated outcomes, e.g., meaning, relevance, and persistence, than the overall amount of motivation (Utvær \& Haugan, 2016). Students with extrinsic life goals tend to have lower life satisfaction, self-esteem, and self-actualization (e.g., Ümmet, 2015), while the autonomous academic motivation relates to higher achievement and enhanced well-being (Soenens \& Vansteenkiste, 2005).

Among the most commonly used scales to measure the regulation of motivation according to SDT is the Academic Motivation Scale (AMS, Vallerand et al., 1992), though, very few studies so far have been applied AMS for graduate students at master level. It was found that graduate students are not intrinsically motivated, although there could be differences between the study programs (Hegarty, 2010) and older graduate students could show higher levels of internal motivation (McCollum \& Kajs, 2007).

Various life changes, such as entering graduate studies, invite us to become engaged in processes of self-reflection and meaning-making. According to Parks (2000) (as cited in Quinlan, 2011, p. 8), "students are in a time of change, in which they must not only deconstruct old meanings and ways of making meaning, but reconstruct a sense of purpose in their own life that integrates expanded perspectives and worldviews". 
The Self-Confrontational Method, used in this study to discover the personal meaning of graduate students, is based on DST (Hermans \& Hermans-Konopka, 2010), drawing from narrative psychology, in which, among other things, people are considered as story-tellers. Conscious personal meaning is generated both by cognitive processes that construct different selves at different times (Hermans, Kempen, \& van Loon, 1992) and by self-organization and self-explication of one's own emotional experience. People are constantly representing themselves to themselves and to others in images, actions, and narratives, and they continuously construct views of themselves in consciousness (Greenberg \& Pasquale-Leone, 2001). Since the people are always situated in time, place and space, the meaning they attach to their most important experiences, will change depending on the stages in their life and the context in which they operate. Every recollection of an event, all circumstances that individuals have been going through, have touched them and will influence their perspective on their life and themselves (Visser, 2016). Thus, to study personal meaning, researcher has to ask people to describe several concrete interrelated acts and events, playing a significant role in their daily lives (Hermans \& Hermans-Jansen, 1995).

Therefore, the presented mixed method research aims to explore the differences in personal meaning of academic experience for graduate students with intrinsic and extrinsic academic motivation. The general research question regarding the differences in personal meaning for graduate students with intrinsic and extrinsic academic motivation was extended by quantitative sub-questions: 1) What types of academic motivation dominate in this sample of graduate students? 2) What are the quantitative differences in narrative themes related to the personal meaning of graduate studies obtained from the answers of intrinsically and extrinsically motivated students? and qualitative sub-questions: 1) What narrative themes related to the personal meaning of graduate studies appear from the qualitative data of graduate students? 2) What qualitative differences if any could be discovered in the narrative themes of intrinsically and extrinsically motivated graduate students?

\section{Participants and procedure}

The convenience sample recruited at the classrooms of Daugavpils University (Latvia) consisted of 128 graduate students (105 female/23 male) with the mean age of $29.1(\mathrm{SD}=8.67)$ and mean work experience of 7.12 years $(\mathrm{SD}=9.12)$; the sample included students from the 1st year (45.9\%), 2nd year (20.8 \%) and 3rd year (20.1 \%) of studies enrolled in Psychology (18.1 \%), Education (56.3\%) and Management (14.6\%) programms. Their satisfaction with income ranged from sooner/fully unsatisfying (38.9\%), partly satisfying (32.6\%) to fully/almost satisfying (17.4\%). The data in written form was 
Pipere \& Iliško, 2018. Personal Meaning of Academic Experience: a Comparison of Intrinsically and Extrinsically Motivated Graduate Students

collected by the main author administering the measures to the groups of participants during their classes. The informed consent from participants was acquired before the administration of the survey, ensuring the confidentiality and anonymity regarding the received data.

\section{Measures}

Academic Motivation Scale (AMS-C28, Vallerand et al., 1992). The modification of college version of AMS was used to assess the academic motivation of graduate students as to divide them into groups with intrinsic and extrinsic motivation. This 28-item instrument includes three subscales of Intrinsic motivation (IM) (know, accomplish things, experience stimulation), three subscales of Extrinsic motivation (EM) (external, introjected, and identified regulation) and Amotivation (absence of IM or EM). The AMS items were rated on a scale ranging from $1=$ does not correspond at all to $7=$ corresponds exactly. Cronbach alpha for seven subscales varied from 0.64 to 0.78 (in original version from 0.62 to 0.86 ). IM item example (to know): "Because my studies allow me to continue to learn about many things that interest me." EM item example (external regulation): "In order to have a better salary later on"; Amotivation item example: “I can't understand what am I doing in graduate studies". The construct validity of AMS was tested with the factor analysis. Principal Component Analysis revealed three factors aligning with the theoretical concept of AMS: the Component 1 loaded on three IM scales, Component 2 loaded on three EM scales, Component 3 loaded on amotivation scale.

Self Confrontation Method (SCM, Hermans \& Hermans-Jansen, 1995). As essentially qualitative method focusing on the personal meaning, the SCM as a narrative method has been used for understanding emotional patterns and themes associated with adaptation to life challenges (Lyddon, Yowell, \& Hermans, 2006). Originally, it was constructed as an idiographic instrument intended to provide the space for the participant to construct valuations during the interview with a psychologist or psychotherapist, rate these valuations according to specific affective indices and, finally, evaluate and integrate the results of the method. Valuations are valuable events located in time and space reflecting the personal meaning of person (Visser, 2016). For this study the SCM was adapted to disclose the narrative themes (valuations) embodying the personal meaning of graduate students' academic life. The SCM was administered in paper-pencil format as a qualitative survey comprising five open-ended questions ('triggers') to identify anything significant in the student's life (related to past, present and future) 
associated with his/her graduate studies:

1) Was there in the past any person, experience, or circumstances that greatly influenced your life and that appreciably affects your present existence as graduate student?

2) Is there in your present existence any person or circumstances that exerts a significant influence on you as graduate student?

3) Do you foresee anything that will be of great importance for or exert a major influence on your future life after graduate studies?

4) Do you feel that a certain person or circumstance will exert a significant influence on your future life after graduate studies?

5) Is there any future goal of object that you expect will play an important role in your life after graduate studies?

The students' answers were analysed by both authors using an inductive approach to thematic analysis with the aim of identifying prominent and consistent narrative themes across participants (Baxter, 1991: 1) all the material was read to obtain an overall impression and to become aware of any preconceptions; 2) the units of meaning with a primary focus on the expression of an idea (i.e. case) (Minichiello, Aroni, Timewell, \& Alexander, 1990), not individual items of language, were identified and coded; 3) these units of meaning were then distilled into broader themes. The number of cases captured within each narrative theme provided an indication of the extent to which this mapping exercise revealed a shared understanding about the themes amongst students. Given the explicit objective of the study to compare two groups of students and large data set, qualitative data were quantified to see the prevalence of themes in entire sample as well as in each subgroup of sample. The percentage of discerned themes for each group allowed to compare the theme "intensity" in these two groups (Boyatzis, 1998). Guest, MacQueen and Namey (2012) do not recommend to use statistical techniques on thematical data due to the sample and data (not truly dichotomous) peculiarities. To simplify the presentation, the separate time perspectives (past, present, future) will not be considered in this analysis and findings will appear in synthesized form containing all time perspectives.

\section{Results Academic motivation of graduate students}

Paired samples t-test to compare intrinsic and extrinsic academic motivation for the given sample showed the dominance of EM. There was a significant difference in the scores of IM $(\mathrm{M}=4.42, \mathrm{SD}=1.05)$ and $\mathrm{EM}(\mathrm{M}=4.84, \mathrm{SD}=$ 1.07): $\mathrm{t}(127)=-4.30, \mathrm{p}<0.000$ (two-tailed). The eta squared statistics (.13) indicated near to large effect size. Amotivation was found at low level $(\mathrm{M}=1.76$, $\mathrm{SD}=1.06$ ). To allow for the qualitative analysis, the sample were divided into two 
Pipere \& Iliško, 2018. Personal Meaning of Academic Experience: a Comparison of Intrinsically and Extrinsically Motivated Graduate Students

groups based on the comparison of EM and IM average aggregate scores for each student: EM group $(n=86)$ included students with larger score for EM scales, IM group $(n=39)$ included those with larger score for IM scales. Three students representing amotivation were excluded from the further analysis.

\section{Personal meaning of academic experience: qualitative analysis}

The narrative themes related to the personal meaning of academic experience associated with graduate studies will appear together with the number of meaning units discerned from the body of answers of the whole sample and textual illustrations of qualitative differences in the themes featured by IM and EM students.

The most frequent theme regarding the students' academic experience were motivation and support from influential persons $(n=308)$.

The teachers at school and university $(n=106)$ were mentioned most often; following examples of quotations illustrate the EM students' answers regarding their school teachers described mostly as the role models: my teachers had an impact on me in the past, now I evaluate the situations exactly as they would do; I would like to attain such level of professionalism as my best teacher had (still has); I recall several teachers at school and later at university whom I would like to follow. IM students stressed the impact in terms of motivation for selfdevelopment: I had teachers who taught me to enjoy the learning process; although my communication with the advisor of my bachelor work has stopped, her advices and support still influence my life today; the scientific advisor of my master thesis gives me the green light for self-development and self-improvement.

The next largest group of influential persons was family $(n=103)$. EM students tried to avoid the feelings of guilt for disappointment of family members: I would not want to disappoint my parents after graduating from Bachelor studies; my husband strongly supports me, he hopes that I will graduate master studies, I cannot disappoint him; my parents have always encouraged me in difficult moments, thanks to their assertion I am graduate student; may be it is my older sister, as she graduated Master studies and what about me? Am I worse? No! IM students often stressed the support for their own choice: support and encouragement from my family helped me to implement my wishes and goals; parents help me a lot, they want me to reach my goals; support from father since I started my psychology studies, his pride about the continuation of studies; my mother heavily fought for my education and after grade 9 I fully understood the importance of education and started my own, un-imposed, learning journey.

The students also felt an impact from other persons $(n=36)$ like classmates, relatives, administration at work: in the past my boss urged me to enter the studies; my course-mates from bachelor studies; my classmate encouraged me to go to 
university (EM students); my relatives say that I need to study; understanding and kindness of the administration at my current workplace (IM students). Interesting theme was colleagues at work $(\mathrm{n}=22)$ that had an influence both on IM and EM students: my colleagues at work already have master degree, they serve as a role model for me; my colleagues are waiting for my graduation. Quite large number of students ( $\mathrm{n}=21)$ (mostly with IM) replied that they have chosen the studies and proceed on their own: to enter the graduate studies was my own idea; everything happens in my life because of my own motivation; no person has an impact on me now, also, there are no circumstances pushing me to study, everything is my own wish; I decided to study on my own, although many were against it. Yet, I was very stubborn and did it my own way (despite my enemies!). Rather important persons, especially for students with EM, were their friends $(\mathrm{n}=18)$ : my friends who already study at master program; my best friend is beside me and always supports me; my best friend is at the 2nd year of graduate studies now; my friends and relatives who already ask my advice regarding the career opportunities.

Less frequent theme in comparison to influential persons was work, career, professional development $(n=182)$. The EM students concentrated on employment-related instrumental benefits of education: I entered graduate studies, since I needed pedagogical education to continue my work at school; [to enter studies] was prompted by refusal to take up the managerial position; failure to find job in a field of psychology; wish to find a good job. IM students stressed the professional development and helping people: my professional development is very essential for me; it is important for me to become a well-trained expert, I want to help people, thus, I need the graduate studies to obtain the relevant practical experience; one need continuous professional development - graduate studies are one of ways selected voluntarily by myself; I would like to become a psychologist, to help people in difficult situations, this aim motivates my studies.

Quite large number of cases was associated with studies/writing master thesis ( $\mathrm{n}=65)$ : it is very important for me to reach the aim - Master degree, to write and successfully defend the master thesis; it is very important for me to attend the classes at university; to work on the Master thesis, do the research, read special literature; I want to proudly submit my thesis (EM students), I would like to know more, understand what does it mean - graduate studies; conferences, seminars, courses will extend my perspective on different topics (IM students).

The theme of personal development was mentioned less often ( $n=55)$. EM students focused more on personal interests, need for education: I always had an interest in languages, work with children; this helps me to continue my way toward master degree; so much is needed for the individual to develop into personality and integrate in society, one needs to be educated. IM students mentioned intellectual development and need for extra knowledge: I got a feeling 
Pipere \& Iliško, 2018. Personal Meaning of Academic Experience: a Comparison of Intrinsically and Extrinsically Motivated Graduate Students

that I am unable to further my intellectual development without the help; need for extra knowledge; I like to delve deeply into the new theories.

Several students mentioned factors inhibiting successful studies $(n=49)$ and the answers did not differ significantly for EM and IM students - these were mostly external conditions: I have a small child who asks attention and leaves no time for studies; very large work load leaves no time and resources for master studies; I am unemployed now, it has the negative consequences on my emotional state, but at least I have time to study.

Past experience leading to master studies $(n=45)$ was described from different angles: been 11 years old I was able to dissuade person from suicide, this encouraged me to study psychology and also to enter master studies; probably it was my good marks, without them I even would not think about graduate studies; international summer camp after grade 9 helped me to choose a work related to English and French.

Diverse application of knowledge/further studies $(n=34)$ was specified mostly by IM students: I am planning to enter doctoral studies; in future I would like to continue my studies, engage in self-realization; I would like to participate in projects, continue my education; in future I would like to develop the decent set of math exercises for grades 10-12.

\section{Personal meaning of academic experience: quantitative analysis}

Table 1 illustrates the frequency of narrative themes (discussed above) of IM and EM students in terms of their personal meaning of academic experience. Answers from 86 EM students contained 430 cases; 39 IM students created 195 cases.

Table 1 Frequency distribution (\%) of narrative themes from intrinsically/extrinsically motivated graduate students

\begin{tabular}{|l|c|c|c|}
\hline \multirow{2}{*}{\multicolumn{1}{|c|}{ Narrative Theme }} & \multicolumn{2}{c|}{ Distribution of Frequency (\%) } & \multirow{2}{*}{$\begin{array}{c}\text { Difference } \\
|\mathbf{E}-\mathbf{I}|\end{array}$} \\
\cline { 2 - 3 } & EM students (E) & IM students (I) & \\
\hline External support & $\mathbf{3 6 . 3}$ & $\mathbf{3 2 . 3}$ & 4.0 \\
\hline Work/career & $\mathbf{2 0 . 8}$ & $\mathbf{1 7 . 9}$ & 2.9 \\
\hline Personal development & $\mathbf{8 . 5}$ & $\mathbf{1 3 . 7}$ & 5.2 \\
\hline Past experience & 7.0 & 5.7 & 1.3 \\
\hline Master thesis/studies & 6.0 & 6.2 & 0.2 \\
\hline Inhibiting factors & 4.0 & 5.3 & 1.3 \\
\hline Further studies & 2.5 & 6.2 & 3.7 \\
\hline Other & 4.4 & 5.1 & 0.7 \\
\hline No answer & 10.5 & 7.6 & 2.9 \\
\hline
\end{tabular}

Note. The numbers in bold represents the highest percentage for each group of students. 
The most frequently mentioned themes both for IM and EM students were external support, work/career and personal development (see Table 1). The larger differences between IM and EM graduate students were discovered in following themes: personal development, further studies, factors inhibiting graduate studies were more frequent for IM students, while external support, work/career, and past experience influencing current academic life were mentioned more often by EM students. Writing master thesis and current studies were similarly important both for IM and EM students. Interestingly, that EM students decided not to provide any answer more frequently than IM students.

\section{Discussion and conclusions}

In the selected sample of graduate students, the EM was dominating type of motivation followed by IM, while amotivation was at a very low level, thus confirming the idea about the concurrent influence of IM and EM and coinciding with the results obtained from graduate students at US university (Hegarty, 2010).

Largest group of themes for the whole sample of students were motivation and support from influential persons, next two considerably smaller themes referred to work/career and personal development. This could be explained by the fact that almost all graduate students are employed, besides, family and work are recognized as two main spheres of our life (Eby, Maher, \& Butts, 2010). Emphasis on the personal development would show that this aspect of academic experience is important both for IM and EM graduate students already due to the decision by these young adults to enter master studies. Next themes, represented at much smaller rate, were master/thesis and studies and further studies - rather natural occurrence given the specific sample and research context.

The qualitative differences, as well, were discovered in the narrative themes of IM and EM graduate students. According to the SDT, less autonomous students (EM students) viewed their teachers as role models, tried not to disappoint their family and relied on their friends, while more autonomous students (IM students) viewed their teachers as persons improving their motivation for self-development, family as the people supporting their own choice, as well as reported self-chosen studies. These findings are in line with Waterman's proposition (2004), showing that IM in form of personal expressiveness could serve as the third defining dimension of identity, along with exploration and commitment. In a sphere of work and professional development EM students focus on education as an instrument to ensure employment, while IM students stress the professional development and helping people, thus aligning with findings by Spittle, Jackson and Casey (2009), showing that confident interpersonal service reasons to become a physical education teacher were linked with IM, while sport and physical activity reasons were related to EM. The difference related to the continuum of 
Pipere \& Iliško, 2018. Personal Meaning of Academic Experience: a Comparison of Intrinsically and Extrinsically Motivated Graduate Students

self-determination is noticeable also in terms of personal development theme, where EM students are reporting their personal interests and need for education, while IM students focus on their intellectual development and need for extra knowledge. Diverse application of knowledge and further studies were mentioned much often by IM students, confirming the instrumental nature of education for EM students and real interest in knowledge application for IM students. However, it has to be explored, if financial security and higher career status would appear as the mediators between the academic motivation and intention to pursue the further studies.

In line with the SDT, EM students more frequently mentioned support from influential persons and career/professional development, while those with IM personal development and further studies. Though, career and professional development were important also for IM students, as, probably, the professional requirements are already deeply integrated in the motivational structure of young adults. The largest difference between the EM and IM graduate students pertains to the personal development (connected with self-efficacy concept related to competence element of IM) (c.f., Buch, Säfvenbom, \& Boe, 2015).

Thus, it can be concluded: the selected sample of graduate students is more extrinsically than intrinsically motivated. The main themes of personal meaning related to academic experience for the whole sample were motivation and support from influential persons, work/career and personal development. The main differences in personal meaning of IM and EM students relate to the more autonomous nature of academic experience of IM students, for them graduate studies are step forward in the process of their self-development, enhancement of personal knowledge in order to help people, while for EM students graduate education also is necessary, but endowed with mostly instrumental value.

Among the limitations of given study the lack of gender balance, time consuming approach/tiredness of respondents during the survey, different sociodemographical profile of motivation groups, and lack of inter-rater reliability calculation should be mentioned.

These results would be of interest for directors of graduate study programs, the student guidance sector and for psychologists working with young adults. Understanding the relationships between the academic motivation and personal meaning of academic experience may help to develop more effective teaching strategies and institutional support of graduate students. Teaching graduate students with EM, university teachers might earn their authority first and then build the learning collaboration on it, at the same time orienting the teaching process toward the theoretical knowledge and practical skills necessary for workplace. Students with IM might be more open to master self-regulated learning strategies and engage in acquisition of broad knowledge foundation needed for further education. The results can encourage the different avenues for 
the further investigation in this field, for instance, regarding the comparison of academic achievement and learning strategies of IM and EM graduate students.

\section{References}

Astin, A. (1993). What matters in college: Four critical years revisited. San Francisco: JosseyBass.

Baker, R. W., \& Siryk, B. (1984). Measuring adjustment to college. Journal of Counseling Psychology, 31, 179-189.

Baxter, L. A. (1991). Content analysis. In B. M. Montgomery \& S. Duck (Eds.), Studying interpersonal interaction (pp. 239-254). New York: The Guilford Press.

Boyatzis, R. E. (1998). Transforming qualitative information. Sage: Cleveland.

Buch, R., Säfvenbom, R., \& Boe, O. (2015). The relationships between academic self-efficacy, intrinsic motivation, and perceived competence. Journal of Military Studies, 6, 1-17.

Deci, E. L., \& Ryan, R. M. (2000). The "what” and "why” of goal pursuits: Human needs and the self-determination of behavior. Psychological Inquiry, 11, 227-268.

Deci, E. L., \& Ryan, R. M. (2008). Facilitating optimal motivation and psychological wellbeing across life's domains. Canadian Psychology,49, 14-23.

Deci, E. L., \& Ryan, R. M. (2014). Autonomy and need satisfaction in close relationships: Relationships motivation theory. In N. Weinstein (Ed.), Human motivation and interpersonal relationships: Theory, research, and applications (pp. 53-73). Dordrecht, Netherlands: Springer.

Eby, L. T., Maher, C. P., \& Butts, M. M. (2010). The intersection of work and family life: The role of affect. Annual Review of Psychology, 61, 599-622.

Eynde, P., \& Turner, J. (2006). Focusing on the complexity of emotion issues in academic learning: A dynamical component systems approach. Educational Psychology Review, 18 (4), 361-376.

Greenberg, L., \& Pascual-Leone, J. (2001). A dialectical constructivist view of the creation of personal meaning. Journal of Constructivist Psychology, 14, 165-186.

Guest, G., MacQueen, K. M., \& Namey, E. E. (2012). Applied thematic analysis. Sage Publications, Inc. Thousand Oaks.

Hegarty, N. (2010). Application of the Academic Motivation Scale to graduate school students. The Journal of Human Resource and Adult Learning, 6 (2), 48-56.

Hermans, H. J. M., \& Hermans-Jansen, E. (1995). Self-narratives: The construction of meaning in psychotherapy. New York: Guilford Press.

Hermans, H. J. M., \& Hermans-Konopka, A. (Eds.) (2010). Dialogical Self theory. Positioning and counter-positioning in a globalizing society. Cambridge University Press.

Hermans, H. J. M., Kempen, H. J. G., \& Van Loon, R. (1992). The dialogical self: Beyond individualism and rationalism. American Psychologist, 47, 23-33.

Lepper, M. R., Corpus, J. H., \& Iyengar, S. S. (2005). Intrinsic and extrinsic motivation orientations in the classroom: Age differences and academic correlates. Journal of Educational Psychology, 97, 184-196.

Lyddon, W. J., Yowell, D. R., \& Hermans, H. J. M. (2006). The self-confrontation method: Theory, research, and practical utility. Counselling Psychology Quarterly, 19 (1), 27-43.

Minichiello, V., Aroni, R., Timewell, E., \& Alexander, L. (1995) In-depth interviewing: Principles, techniques, analysis (2nd ed.). Melbourne: Longman. 
Pipere \& Iliško, 2018. Personal Meaning of Academic Experience: a Comparison of Intrinsically and Extrinsically Motivated Graduate Students

Quinlan, K. M. (2011). Developing the whole student: leading higher education initiatives that integrate mind and heart. University of Oxford: Oxford Learning Institute, Leadership Foundation for Higher Education.

Ryan, R. M., \& Deci, E. L. (2000). Self-determination theory and the facilitation of intrinsic motivation, social development, and well-being. American Psychologist, 55, 68-78.

Soenens, B., \& Vansteenkiste, M. (2005). Antecedents and outcomes of self-determination in three life domains: The role of parents'and teachers' autonomy support. Journal of Youth and Adolescence, 34, 589-604.

Spittle, M., Jackson, K., \& Casey, M. (2009). Applying self-determination theory to understand the motivation for becoming a physical education teacher. Teaching and Teacher Education, 25, 190-197.

Stover, J. B., de la Iglesia, G., Boubeta, A. R., \& Liporace, M. F. (2012). Academic Motivation Scale: adaptation and psychometric analyses for high school and college students. Psychology Research and Behavior Management, 5, 71-83.

Utvær, B. K. S., \& Haugan, G. (2016). The academic motivation scale: dimensionality, reliability, and construct validity among vocational students. Nordic Journal of Vocational Education and Training, 6 (2), 17-45.

Ümmet, D. (2015). Self-esteem among college students: A study of satisfaction of basic psychological needs and some variables, Procedia-Social and Behavioral Sciences, 174, 1623-1629.

Vallerand, R. J., Pelletier, L. G., Blais, M. R., Briere, N. M., Senecal, C., \& Vallieres, E. F. (1992). The Academic Motivation Scale: A measure of intrinsic, extrinsic and amotivation in education. Educational and Psychological Measurement, 52, 1003-1017.

Visser, H. (2016). Self-Confrontation Method: Assessment and process-promotion in career counselling. In H. Hermans (Ed.), Assessing and stimulating a Dialogical Self in groups, teams, cultures, and organizations (pp. 19-36). Springer.

Waterman, A. S. (2004). Finding someone to be: Studies on the role of intrinsic motivation in identity formation. Identity: An International Journal of Theory and Research, 4 (3), 209-228. 